\title{
STUDIES OF THE SPINAL CORD
}

PART I. TOPOGRAPHIC LOCALIZATION WITHIN THE DORSAL SPINO-CEREBELIAAR TRACT IN MACACA MULATTA

ROBERT E. YOSS

Laboratory of Comparative Neurology, Department of Anatomy,

University of Michigan, Ann Arbor ${ }^{1}$

THREE FIGURES

In 1903 Sherrington and Laslett described the arrangement of the fascicles within the dorsal spino-cerebellar tract in the dog, an arrangement which has been rather generally accepted for higher mammals including man. The present paper is concerned primarily with the topographic localization pattern of the dorsal spino-cerebellar tract in the spinal cord of Macaca mulatta and the projection of this tract upon the cerebellum.

While studying the vascular supply of the macaque spinal cord, the author (Yoss, '50) had the opportunity of examining a number of cords in which lesions at various levels had produced degeneration within the dorsal spino-cerebellar tract. This material permitted a study of the position of the degenerated fibers arising from specific segments as they ascended in the spinal cord.

\section{MATERIAL AND METHODS}

In 8 monkeys spinal cord lesions were produced by the experimental occlusion of various blood vessels supplying the spinal cord. These lesions were located at lumbar and lower thoracic levels. Additional material has been obtained in three monkeys by dorsal spino-cerebellar tractotomy at

1 This work was aided by a grant from the Alphonso Morton Clover Medical Research Fund. 
upper thoracic and cervical regions. The animals were examined neurologically during a two-week post-operative period and then sacrificed. The case reports of the monkeys with vascular lesions of the cord have been given (Yoss, '50). The cerebellum, brain stem and various levels of the spinal cord were stained by the Swank and Davenport ('35) modification of the Marchi technique. Some of the cerebella were sectioned in the sagittal plane, and this material proved to be most useful in determining the projection of the dorsal spino-cerebellar tract on the cerebellum.

The author wishes to express his gratitude to Professor Elizabeth C. Crosby for her great help and encouragement during the surgical procedures and during the preparation of this paper. The photomicrographs have been prepared by Mr. George J. Smith and the illustration by Mrs. Joy N. Mara, research technicians in the Department of Anatomy.

\section{Topical arrangement of the fibers in the dorsal spino-cerebellar tract}

Eleven monkeys were used for this report but, because of some duplication of material, only the detailed information obtained from the spinal cords of 6 monkeys with lesions at the levels of L3, L2, T12, T10, T4, or C4 will be given. Such lesions are illustrated by appropriate photomicrographs. It should be emphasized, however, that the cords from all of the 11 monkeys revealed the pattern of topographic localization within the dorsal spino-cerebellar tract which is to be presented.

Only a very few fibers of the dorsal spino-cerebellar tract arise from below the third lumbar segment, as is shown in a monkey with a cord lesion at this level (fig. 2, d). These few degenerated fibers are located deep within the lateral white column of the lumbar cord; they shift directly dorsad so that at about T11 they have gained a position between the dorsal horn and Lissauer's tract dorsomedially and the 
pyramidal tract and the more rostrally arising fibers of the dorsal spino-cerebellar tract ventrolaterally. Only a few of them approach the surface of the spinal cord, and then only when they lie dorsally where some of them are immediately ventral to the entrance of the dorsal root. The dorsal spinocerebellar fibers arising from below the level of L3 maintain this relative position in their ascent through the thoracic cord. On reaching the cervical enlargement, the fibers shift farther dorsad into a more compact bundle which lies immediately dorsal to the pyramidal tract but with some fibers still on the surface of the cord (fig. 2, d). Such degenerated surface fibers extend about $0.3 \mathrm{~mm}$ ventrolaterad from the dorsal root.

In another monkey a lesion placed at the second lumbar segment resulted in a great increase in the number of degenerated fibers of the dorsal spino-cerebellar tract as compared with the number seen when the lesion was located at L3 (fig. $2, c)$. Immediately above the lesion at $L 1$, the fibers of the dorsal spino-cerebellar tract lie, as a large, fairly compact bundle, deep within the lateral white column and adjoining. the ventral portion of the dorsal horn, ventral to the pyramidal tract. None of these fibers have attained the surface of the cord at this level but many fascicles can be seen extending laterad. Most of them turn laterad in the lower thoracic region to form a layer of degenerated fibers along the surface of the lateral white column between Lissauer's tract dorsally and a point approximately equidistant between the dorsal and the ventral roots ventrally. The greater portion of the fascicles are located in the ventral part of the tract at this lower level. Most of these fibers retain a superficial position in their ascent through the thoracic cord but there is a definite tendency for some bundles to shift dorsad so that the fibers are predominantly dorsal at upper thoracie levels. A few fibers (from L3 or below) never lie on the surface of the cord but are found, beginning at lower thoracic levels, between the dorsal horn and Lissauer's tract dorsomedially and the pyramidal tract ventrolaterally. This dorso- 
medial bundle does not increase in size nor change materially in general shape from lower to higher thoracic levels. On reaching the cervical enlargement, all degenerated fibers shift farther dorsad to form a comet-shaped, compact bundle of degenerated fascicles with the head of the comet placed medially and the tail extending ventrolaterad along the surface of the cord for a distance of about 0.8 to $0.9 \mathrm{~mm}$.

The next monkey had two lesions in the central nervous system: a spinal cord lesion located at the 12th thoracic segment and an injury to the right internal capsule. These two lesions were of especial value for contrasting the degenerated fibers of the ascending dorsal spino-cerebellar tract with the descending degenerated bundles of the adjacent pyramidal system. As far as the degeneration in the dorsal spinocerebellar tract is concerned, there is little difference between the localization pattern from the lesion at T12 and that from the previously described lesion, located two segments more caudally, at L2. As would be expected, the more rostrally placed lesion produced a greater degeneration of the tract (fig. 1). Just above the level of the lesion, a large group of degenerated fibers of the dorsal spino-cerebellar system lies deep in the lateral white column ventral to the pyramidal tract, with a few fibers reaching the surface of the cord (fig. 1, d). At the level of T10 (fig. 1, e), some of these fibers have shifted to the surface of the lateral column but with the greater portion of them situated in the ventral region of the tract. A few fascicles lie between the dorsal horn and Lissauer's tract dorsomedially and the pyramidal tract ventrolaterally. This dorsal shift of degenerated fibers continues so that, at mid-thoracic levels, although the general outline of the tract remains the same, the major portion of the degenerated fibers are located dorsally in it with an increase in the number of fibers in its dorsomedial portion (fig. 1, b). On reaching the cervical enlargement (fig. 1 , a), the degenerated fibers again accumulate into a comet-shaped bundle, with perhaps a slightly longer tail to the comet than was seen fol- 
lowing the lesion at $\mathrm{L} 2$. The surface fibers extend about $1 \mathrm{~mm}$ ventrad from the entrance of the dorsal roots.

In a monkey with a cord lesion at the level of $\mathrm{T} 10$, the degenerated dorsal spino-cerebellar tract shows the same general pattern as that described for it in animals having lesions in the lumbar cord and the 12th thoracic segment. Of course, there is a slightly greater number of degenerated fibers as the result of the higher lesion. Moreover, although most of the degenerated fibers are loteated, in the cervical region, in the most dorsal portion of the dorsal spino-cerebellar tract, there are some fibers extending ventrad near the surface of the cord for a distance of about $1.2 \mathrm{~mm}$ (fig. 2, b).

A dorsal spino-cerebellar tractotomy at the level of $\mathrm{T} 4$ (fig. 2, a) produced a thick, even band of degenerated fibers along the surface of the upper thoracic cord. At cervical levels this band of fibers extends ventrad from the dorsal roots for a distance of $2.2 \mathrm{~mm}$. The ventral third of the tract does not reach the surface of the cord and is formed by only a few large fibers.

A lesion at the 4th cervical segment involving the dorsal spino-cerebellar tract, as well as a portion of the ventral spino-cerebellar and the lateral spino-thalamic systems, produced only a slight increase in the number of degenerated fibers of the dorsal spino-cerebellar tract as compared with the number seen in this tract following the lesion at T4. This increase is manifested by a very slight ventral extension of the bundle and, even more, by a pronounced thickening of this ventral extension. The fact that the cord lesion is at the level of $\mathrm{C} 4$ does not imply that these additional degenerated fiber's arose from cervical levels, but only that such fibers have their origin somewhere between the levels of $\mathrm{C} 4$ and $\mathrm{T} 4$. It is felt that the most likely origin is from the uppermost thoracic segments.

When only a few fascicles of a tract are degenerated it is possible to count the individual fibers involved with reasonable accuracy. Thus, the cord material obtained from the monkey with a lesion at the third lumbar segment (fig. 2, d) 
provided a wonderful opportunity to count the relatively few degenerated fibers in the system at various levels of the cord and thereby determine the approximate length of these fibers. Only the large degenerated fibers were counted and the fine scattered granules, some of which undoubtedly represented degenerated fibers of this system, were arbitrarily ignored. Nevertheless, in spite of these known inaccuracies, it was possible to determine whether most of the fibers of this system reach the medulla or whether some of them end at various levels of the spinal cord. Reasonably accurate counts at the levels of $\mathrm{T} 11, \mathrm{~T} 8, \mathrm{~T} 3, \mathrm{C} 7, \mathrm{C} 3$ and the medulla were made, with the number of degenerated fibers for one side ranging from 41 to 46 at any level, except for the 11th thoracic level where only 33 fibers were found. This count indicates that the fibers of the dorsal spino-cerebellar tract arising from the more candal segments of the spinal cord are all long and that most of them, perhaps all of thens, ascend in the cord to enter the medulla.

However, when, with a higher lesion, the number of degenerated fibers in the dorsal spino-cerebellar system is greatly increased and such fibers are massed together, the outlines of the broken down fibers are obscure and any enumeration of them is, of necessity, grossly inaccurate. Such grossly inaccurate counts were made and the results suggest that most of the fibers of the dorsal spino-cerebellar tract arising from higher levels are also long.

\section{The termination of the fibers of the spino-cerebellar system}

Degenerated fibers of the dorsal spino-cerebellar tract have been traced from the spinal cord to their terminations in the cerebellum. Both transverse and sagittal sections have been studied, the latter proving to be the more valuable for determining the projection pattern on the cerebellum.

Following a cord lesion at the second lumbar segment, degenerated fibers of the dorsal spino-cerebellar tract were 
traced to the central lobule, the culmen, the declive, the pyramid, and the uvula. This distribution is by no means uniform. The largest portion of degenerated fibers terminates in the rostral half of the culmen and the dorsal part of the central lobule. A definite group of fibers extends to the ventral portion of the pyramid, with a few fibers reaching its dorsal portion. A small number of fascicles project on the uvula and an occasional fiber can be traced to the declive. No degenerated fibers can be followed to the lingula, the nodule, the tuber, or the folium vermis. Fibers from the ventral spino-cerebellar tract, also, can be traced to the culmen and the central lobule. All of the spino-cerebellar fibers project to the vermis, with the exception of a few, scattered fascicles which extend into the hemisphere portion of the anterior lobe. Material prepared after lesions at various levels confirmed the above described spino-cerebellar projection.

It is not possible from the material at present available to project the fibers arising from each segment of the spinal cord to a specific portion of the cerebellum. As a matter of fact, it appears unlikely that there is a pure segmental pattern projected by the spino-cerebellar systems to this brain area, since the material prepared following the L2 lesion showed degeneration throughout the whole cerebellar distribution of the dorsal spino-cerebellar tract. Nevertheless, from certain indirect evidence, not as yet ready to report, the author is inclined to believe that a given level of the spinal cord does distribute predominantly, even though not exclusively, to a specific portion of the cerebellum; i.e., that fundamentally there is an incomplete, but nevertheless demonstrable, localization pattern. Chang and Ruch ('49) have presented incomplete anatomic evidence that such a pattern exists. Many physiologic studies of functional localization upon the cerebellum have been made such as those of Snider and Stowell ('42, '44), Snider ('50), and others, but they are not directly pertinent to the material discussed in this paper. 


\section{DISCUSSION AND SUMMARY}

The pattern of localization within the dorsal spino-cerebellar tract, as deseribed by Sherrington and Laslett ('03) for the dog, was one of simple stratification with the longest fibers of the tract - i.e., those from more caudal segments at the periphery and the shortest fibers of the system most medially. This pattern has been confirmed by MacNalty and Horsley ('09) for the cat, the dog, and the monkey.

There is a considerably different pattern of localization in the monkey, with the longest fibers of the dorsal spino-cerebellar tract shifting dorsad as they ascend in the spinal cord. Fibers of intermediate length are located just ventral to the longest fibers and, finally, fibers from the upper thoracic segments lie in the most ventral portion of the tract at cervical levels.

There is some confirmatory evidence in the literature that there is such a dorsoventral arrangement of fibers in the dorsal spino-cerebellar system. Mott (1892), working with the monkey, and Pass ('33), studying degenerated fiber preparations in the cat, indicated in their figures (although they did not comment on the fact) that the longest fibers of the dorsal spino-cerebellar tract lie most dorsally at cervical levels. Collier and Buzzard ('03) stated that, in man, the longest fibers of the dorsal spino-cerebellar system are in its most dorsal portion as they ascend toward the brain. In 1927, Beck, in a series of experiments on the cat, was unable to establish any localization pattern in this fiber system and so did not confirm the results of Sherrington and Laslett. Gardner and Cuneo ('45) report that, in man, there was a tendency at cervical levels for the dorsal spino-cerebellar tract fibers to shift dorsad.

The pattern of localization for the dorsal spino-cerebellar tract of the monkey is indicated in figure 3 which is a diagrammatic representation of our conception of the pattern at cervical segments. It should be noted that a lesion of the tract at any of the indicated levels will result in a degeneration in the cervical cord of that portion of the tract that is dorsal 
and dorsomedial to its respective indicated line. As has been previously pointed out, the additional degeneration in the tract, as a result of a lesion at the 4th cervical segment, should not be taken to imply that these fibers arise from cervical cord segments. At the present time the writer has no evidence, either for or against the statement which is sometimes made, that the dorsal spino-cerebellar system also receives fibers from cervical cord gray (Collier and Buzzard, '03; Ferraro and Barrera, '35a; Cooper and Sherrington, '40).

Apparently a relatively large portion of the fibers of the dorsal spino-cerebellar tract in the monkey arise in the lumbar and lower thoracic segments of the spinal cord (fig. 3). This has been pointed out by other investigators for man (Collier and Buzzard, '03) and for the cat (Beck, '27). As might be expected from the above observation, a relatively large proportion of the cells of Clarke's column are in lumbar and lower thoracic levels (Mott, 1888; Bruce, '01; Bok, '28; Pass, '33; and others).

In the spinal cord material available, there are no degenerated fibers which appear to correspond to the intermediate spino-cerebellar tract described by Pellizzi (1895), Beck ('27) and Anderson ('43). A few degeneration granules can be seen at some levels in several of the monkey cords between the degenerated fibers of the dorsal and the ventral spinocerebellar tracts but these granules are few and inconstant.

The dorsal shift of the fibers of the dorsal spino-cerebellar tract is greatest in the cervical enlargement where, among other things, the posterior columns are greatly increased in size. The enlargement in the posterior columns may be partially responsible for this dorsal shift. As has been pointed out by Weil ('27) and Ariëns Kappers, Huber and Crosby ('36), the relative size of the posterior columns increases in higher mammals and therefore, in animals such as the dog, the dorsal shift probably is not as apparent as that seen in the monkey. One might expect then, the dorsoventral pattern in the dorsal spino-cerebellar system to be most marked in primates. 
It is self-evident that this localization pattern within the dorsal spino-cerebellar tract shows a marked resemblance in many particulars to that of certain other fiber systems of the spinal cord. There is a dorsomedial to ventrolateral pattern within the posterior columns with the longest fibers situated dorsomedially and the shortest fibers ventrolaterally (Winkler, '18; Bok, '28; Ferraro and Barrera, '35b; Foerster, '36; Walker and Weaver, '42) and a dorsolateral to ventromedial pattern within the lateral spino-thalamic tract with the longest fibers located dorsolaterally and the shortest fibers ventromedially (Hyndman and Van Epps, '39; Walker, '40; Weaver and Walker, '41). The dorsal spino-cerebellar tract, in its intermediate position between these fiber systems, shows a dorsoventral pattern very similar to that of the above systems, with the longest fibers situated dorsally and the shortest fibers ventrally.

The projection of spino-cerebellar fibers upon the cerebellum, as here described, is essentially in agreement with the reports of Bruce (1898), MacNalty and Horsley ('09), Brodal and Jansen ('41), Grundfest and Campbell ('42) and others. The major portion of the fibers pass to the vermis part of the anterior lobe but a few fibers distribute to the pyramid, the uvula, and the declive.

\section{LITERATURE CITED}

ANDERson, R. F. 1943 Cerebellar distribution of the dorsal and ventral spinocerebellar tracts in the white rat. J. Comp. Neur., $79: 415-423$.

Ariêns Kappers, C. U., G. C. Huber and E. C. Crosby 1936 The comparative anatomy of the nervous system of vertebrates, including man. The Maemillan Company, New York. 2 vols.

BECK, G. M. 1927 The cerebellar terminations of the spino-cerebellar fibres of the lower lumbar and sacral segments of the cat. Brain, 50:60-98.

BoK, S. T. 1928 Das Rückenmark. v. Möllendorff's Handbuch der mikroskopischen Anatomie des Menschen, 4: 478-578, J. Springer, Berlin.

Brodal, A., and J. Janswin 1941 Beitrag zur Kenntnis der spino-cerebellaren Bahnen beim Menschen. Anat. Anz., 91: 185-195.

BrUCe, A. 1898 Note on the upper terminations of the direct cerebellar and ascending antero-lateral tracts. Brain, 21: 374-382.

1901 A topographical atlas of the spinal cord. Williams and Norgate, London. 16 pp., $32 \mathrm{pl}$. 
Chang, H., and T. C. RUCH 1949 The projection of the caudal segments of the spinal cord to the lingula in the spider monkey. J. Anat., 83: 303-307.

Colister, J., AND E. F. Buzzard 1903 The degenerations resulting from lesions of posterior nerve roots and from transverse lesions of the spinal cord in man. A study of twenty cases. Brain, $26: 559-591$.

Cooper, S., AND C. S. ShgrRINGToN 1940 Gower's tract and spinal border cells. Brain, 63: 123-134.

Frrraro, A., and S. E. Barrera 1935a The effects of lesions of the dorsal spino-cerebellar tract and corpus restiforme in the Macacus rhesus monkey. Brain, 58: 174-202.

1935b Posterior column fibers and their termination in Macacus rhesus. J. Comp. Neur., 62: 507-530.

Foerster, O. 1936 Symptomatologie der Erkrankungen des Rückenmarks und seiner Wurzeln. Bumke u. Foersters Handbuch der Neurologie, 5 : 1-403, J. Springer, Berlin.

GARDNBR, E., AND H. M. CUNEO 1945 Lateral spinothalamie tract and associated tracts in man. Arch. Neur. and Psychiat., Chicago, 53: 423-430.

GrundFEst, H., AND B. CaAPBell 1942 Origin, conduction and termination of impulses in the dorsal spino-cerebellar tract of cats. J. Neurophysiol., $5: 275-294$.

Hyndman, O. R., ANd C. VAN EPPs 1939 Possibility of differential section of the spinothalamie tract. A clinical and histologic study. Arch. Surg., 38: 1036-1053.

MACNALTY, A. S., AND V. HoRsLex 1909 On the cervical spino-bulbar and spino-cerebellar tracts and on the question of topographical representation in the cerebellum. Brain, 32:237-255.

MoтT, F. W. 1888 Microseopical examination of Clarke's column in man, the monkey, and the dog. J. Anat. Physiol., 2E: 479-495.

1892 Ascending degenerations resulting from lesions of the spinal cord in monkeys. Brain, 15 : 215-229.

PAss, I. J. 1933 Anatomic and functional relationships of the nucleus dorsalis (Clarke's column) and of the dorsal spinocerebellar tract (Flechsig's). Arch. Neur, and Psychiat., Chicago, 30: 1025-1045.

Pellizzi, G. B. 1895 Sur les dégénérescences secondaires, dans le système nerveux central, à la suite de lésions de la moelle et de la section de racines spinales. Contribution à l'anatomie et à la physiologie des voies cérébelleuses. Arch. ital. Biol., 24: 89-134.

Shbrringron, C. S., AND E. E. LAsletis 1903 Remarks on the dorsal spinocerebellar tract. J. Physiol., 29: 188-194.

SNIDER, R. S. 1950 Recent contributions to the anatomy and physiology of the cerebellum. Arch. Neur. and Psychiat., Chicago, 64: 196-219.

SNIDER, R. S., AND A. STOWELL 1942 Evidence of a representation of tactile sensibility in the cerebellum of the cat. Fed. Proc., 1: 82 .

1944 Receiving areas of the tactile, auditory, and visual systems in the cerebellum. J. Neurophysiol., $7: 331-357$.

SWANK, R. L., AND H. A. DAvENPoRT 1935 Chlorate-osmic-formalin method for staining degenerating myelin. Stain Tech., 10: 87-90. 
Walk BR, A. E. 1940 The spinothalamie tract in man. Arelı. Neur. and Psychiat., Chicago, $43: 284-298$.

WALKER, A. E., AND T. A. WEAVER 1942 The topical organization and termination of the fibers of the posterior columns in Macaca mulatta. J. Comp. Neur., 76: 145-158.

WeAver, T. A., AND A. E. WALKER 1941 The topical arrangement within the spino-thalamic tract of the monkey. Arch. Neur. and Psychiat., Chicago, 46:877-883.

WeIL, A. 1927 A comparative quantitative study in proprioceptive tracts of mammals. J. Comp. Neur., at: 61-67.

WinkLfR, C. 1918 Le système nerveux sensitivo-moteur ou système de la sensibilité générale. Opera Omnia, 6:122-259, de erven Bohn, Haarlem.

Yoss, R. E. 1950 Vascular supply of the spinal cord : the production of vascular syndromes. Univ. Mich. med. Bull., 16: 333-345. 
PLATES 


\section{PLATE 1}

\section{EXPLANATION OF FIGURES}

1 Representative cord levels from a monkey with a spinal cord lesion at T12 and a lesion of the right internal capsule. Note the dorsal shift of the degenerated fibers of the dorsal spino-eerebellar tract as they aseend toward the brain. Abbreviations: d.s.c.t., dorsal spino-eerebellar tract; p.y., pyramidal tract. Marehi stain. $\times 7$.

2 Cervical sections from 4 different monkeys with spinal cord lesions at the indicated levels. Note the increase in number of degenerated fibers in the dorsal spino-cerebellar tract as a result of the more rostral lesions. Abbreviation: d.s. c.t., dorsal spino-cerebellar tract. Marehi stain. $\times 7$. 

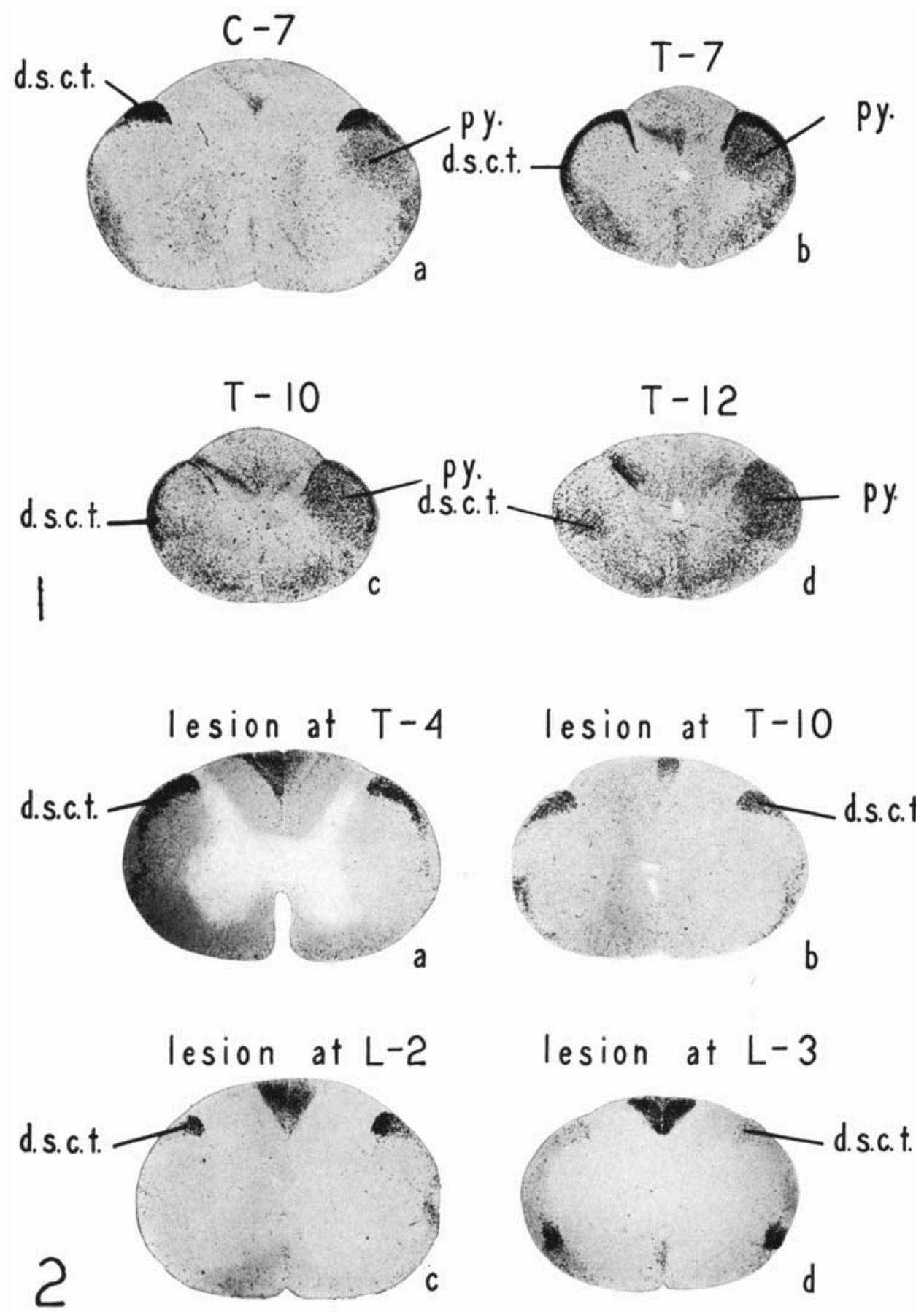


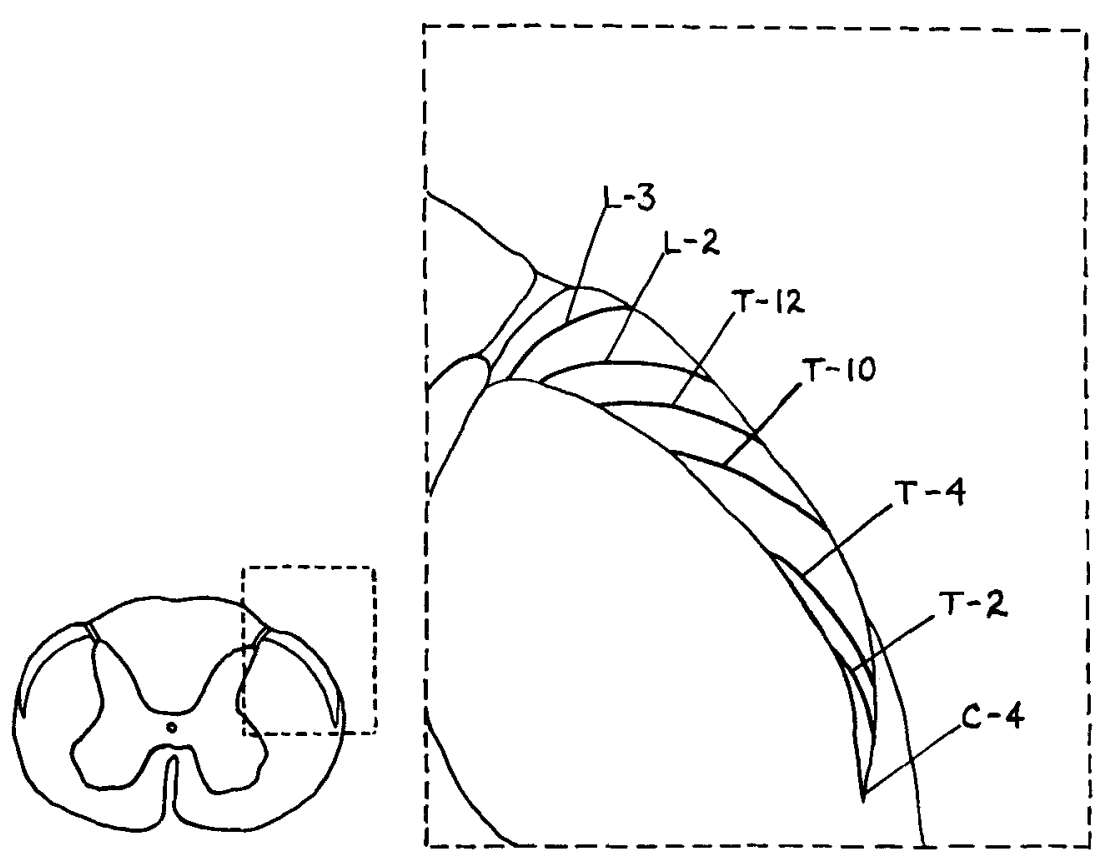

3 A diagrammatic representation of the pattern of localization within the dorsal spinocerebellar tract of the monkey at cervical levels. At each of the indicated levels the portion of the tract arising caudal to that level lies dorsal and dorsomedial to the respective leader. 